\title{
AVALIAÇÃO DE QUALIDADE DE PESCADOS CONGELADOS COMERCIALIZADOS EM FEIRA DE SANTANA/BA
}

\author{
$\underline{\text { Rosilane da Silva Santos }}{ }^{1}$; Fatima Luscher Albinati²; Elisa Teshima ${ }^{3}$ \\ 1. Bolsista PROBIC/UEFS, Graduanda em Engenharia de Alimentos, Universidade Estadual de Feira de Santana, e- \\ mail: rosilanessr@ hotmail.com 2. Orientadora, Departamento de Tecnologia, Universidade Estadual de Feira de \\ Santana, e-mail: flalbinati@uefs.br 3. Professora, Departamento Tecnologia, Universidade Estadual de Feira de \\ Santana, eteshima@uefs.br
}

PALAVRAS-CHAVE: Psicrotróficos; Desglaciamento; Fraude pescado.

\section{INTRODUÇÃO}

O pescado é um alimento rico em proteínas, de fácil digestibilidade, baixo teor de gorduras e rico em ácidos graxos do tipo ômega-3 (Silva et al., 2008). Comparado com outros produtos de origem animal, são alimentos altamente susceptíveis ao processo de deterioração (Franco; Landgraf, 2008). Os microrganismos estão naturalmente presentes na superfície externa (pele e brânquias) e trato intestinal o que contribui para a alta perecibilidade dos pescados. Assim, logo após a pesca ou captura devem ser mantidos sob temperaturas de refrigeração, para preservar a qualidade do pescado até a comercialização (Gonçalves, 2005).

Para garantir a qualidade dos produtos alimentícios, os procedimentos de higienização e a observação das Boas Práticas de Fabricação são fundamentais. Desta forma, o emprego rigoroso de cuidados higiênicos e o atendimento às normas e padrões microbiológicos estabelecidos pela legislação vigente garante ao consumidor proteção contra riscos à sua saúde (Abreu, et al., 2008). Para avaliação da qualidade dos pescados podemos utilizar métodos físico-químicos, microbiológicos e sensoriais. Entre os métodos de conservação de pescado destaca-se o congelamento, podendo-se afirmar ser o melhor método para prolongar a vida útil de produtos alimentícios, mantendo desse modo o flavor, a cor e o valor nutritivo. Durante a estocagem de pescados congelados podem surgir problemas como a deterioração oxidativa, a desidratação, o endurecimento e a perda de água excessiva no descongelamento (Oetterer et al., 2012). Para reduzir os efeitos das alterações bioquímicas que depreciam o pescado congelado é utilizada a tecnologia do glaciamento, que é um processo industrial com o objetivo de proteção do peixe eviscerado e sem pele, evitando a oxidação lipídica, o ressecamento e consequentemente a alteração de sua aparência. O processo é realizado geralmente após o congelamento do pescado, por meio de pulverização de gotículas de água sobre o pescado (Flugel, 2005; Neiva et al., 2015). Porém, com o intuito de lucrar ilicitamente, muitos fabricantes adicionam nessa etapa, uma quantidade de agua superior ao permitido pelo ministério da Agricultura Pecuária e Abastecimento-MAPA, o que caracteriza uma fraude (Ribeiro; Marcello, 2013).

Logo o objetivo deste trabalho foi avaliar a qualidade de pescados congelados comercializados em Feira de Santana/BA, por meio de analises físico-químicas, microbiológica, sensoriais e mensuração do nível de glaciamento, contribuindo assim para a segurança alimentar do consumidor.

\section{MATERIAL E MÉTODOS OU METODOLOGIA (ou equivalente)}


Desglaciamento: Foram coletadas duas unidades de cada amostra de pescado de um mesmo lote, sendo uma destinada à análise microbiológica e a outra às análises sensorial, físico-química e desglaciamento. Foram coletadas 21 amostras em duplicata, obtendo-se 42 embalagens de peixes congelados glaciados. O transporte das amostras foi realizado em caixa isotérmica com gelo, a fim de manter os produtos em seu estado original até a análise. Para a análise de desglaciamento, utilizou-se a metodologia descrita em "Métodos Analíticos Oficiais Fisico-quimicos para Controle de Pescados e seus Derivados" (Brasil, 2011).

Avaliações físico-químicas: As amostras foram analisadas quanto ao $\mathrm{pH}$, de acordo com a metodologia descrita no Manual de análise físico-química de alimentos do Instituto Adolfo Lutz (1985). A leitura do $\mathrm{pH}$ foi realizada com o auxílio do pHmetro digital da marca Hanna, modelo HI99163.

O teste de Eber, conhecido também como teste do gás sulfídrico, foi realizado seguindo os Métodos analíticos de produtos de origem animal (Brasil, 2014).

Avaliação Microbiológica: A contagem de psicrotróficos foi realizada por semeadura em superfície "spread plate", em placas de Petri contendo Plate Count Agar (PCA) e incubadas a $7^{\circ} \mathrm{C} / 10$ dias como indica Silva et al. (2010).

Análises sensoriais e cocção: As características sensoriais (evidência de decomposição, manchas por hematomas, coloração distinta à normal, incisões ou rupturas) e o teste de cocção foram realizados de acordo com a Instrução Normativa $n^{\circ} 25$, de 02 de junho de 2011, visando verificar o frescor do produto (Brasil, 2011).

\section{RESULTADOS E/OU DISCUSSÃO (ou Análise e discussão dos resultados)}

$\mathrm{O}$ processo de glaciamento protege o produto contra o ressecamento e a rancificação causados pela conservação via congelamento, atuando assim como uma camada protetora (Evangelista et al., 2017). Os resultados da análise de desglaciamento estão na Tabela 1.

Segundo o Regulamento Técnico de Identidade e Qualidade para peixe congelado é permitida a realização de glaciamento do peixe congelado, até o limite máximo de $12 \%$ (doze por cento) do peso líquido declarado. Sendo considerada ação fraudulenta qualquer valor acima deste (BRASIL, 2017). Como pode-se observar na Tabela 1 das amostras analisadas 47,6\% se encontram fora dos limites estabelecidos pela legislação, além de $57 \%$ apresentarem após desglaciamento peso inferior ao declarado na embalagem, sendo também considerado fraude.

A legislação brasileira não possui padrões de contagem de psicrotróficos para pescados resfriados e congelados, mas a presença desses microrganismos indica as condições higiênico-sanitárias dos produtos. Segundo Soares (2011 apud International Commissionon Microbiological Specifications for Foods - ICMS) o limite de 5 log UFC/g é indicativo de boa qualidade e o de $6 \mathrm{log}$ UFC/g de qualidade aceitável. Assim, entre as amostras analisadas $57 \%$ apresentaram boa qualidade, $24 \%$ tiveram qualidade aceitável e 19\% estavam em desacordo com os limites estabelecidos ou seja, de baixa qualidade (Tabela 1). De acordo com Pacheco et al. (2004), quando essa contagem é elevada significa que a amostra pode ter ser sido contaminada durante a captura ou beneficiamento, podendo o alimento ter suas características organolépticas alteradas. 
Quando estas alterações são detectadas no produto, o mesmo em geral, apresenta contagem superior a $6 \log$ UFC/g (Soares, 2011).

Tabela 1. Resultados das análises de desglaciamento, contagem de psicrotróficos e $\mathrm{pH}$.

\begin{tabular}{c|c|c|c|c|c|c|c}
\hline Amostra & PPG $(\mathbf{g})$ & PLD $(\mathbf{g})$ & PPD & PG & Log UFC/g & pH & Marca \\
\hline $\mathbf{1}$ & 824,64 & 800 & 696,07 & $16 \%$ & 4,88 & 6,70 & $\mathrm{~A}$ \\
\hline $\mathbf{2}$ & 880,91 & 800 & 825,52 & $6 \%$ & 5,77 & 6,53 & $\mathrm{~A}$ \\
\hline $\mathbf{3}$ & 827,59 & 800 & 696,85 & $16 \%$ & 4,51 & 6,74 & $\mathrm{~A}$ \\
\hline $\mathbf{4}$ & 894,41 & 800 & 826,49 & $8 \%$ & 4,65 & 6,32 & $\mathrm{~B}$ \\
\hline $\mathbf{5}$ & 834,4 & 800 & 680,01 & $19 \%$ & 6,09 & 6,56 & $\mathrm{~A}$ \\
\hline $\mathbf{6}$ & 894,99 & 800 & 789,24 & $12 \%$ & 5,43 & 6,45 & $\mathrm{~B}$ \\
\hline $\mathbf{7}$ & 934,23 & 800 & 820,28 & $12 \%$ & 4,90 & 6,61 & $\mathrm{~A}$ \\
\hline $\mathbf{8}$ & 1059,25 & 1000 & 1000,99 & $6 \%$ & 0,00 & 6,72 & $\mathrm{C}$ \\
\hline $\mathbf{9}$ & 908,50 & 800 & 822,20 & $9 \%$ & 5,15 & 6,30 & $\mathrm{~B}$ \\
\hline $\mathbf{1 0}$ & 815,18 & 800 & 737,52 & $10 \%$ & 6,53 & 6,67 & $\mathrm{~A}$ \\
\hline $\mathbf{1 1}$ & 1113,04 & 1000 & 1006,68 & $10 \%$ & 6,05 & 7,36 & $\mathrm{~B}$ \\
\hline $\mathbf{1 2}$ & 934,13 & 800 & 816,45 & $13 \%$ & 4,70 & 6,61 & $\mathrm{~B}$ \\
\hline $\mathbf{1 3}$ & 694,90 & 500 & 497,40 & $28 \%$ & 4,59 & 6,43 & $\mathrm{D}$ \\
\hline $\mathbf{1 4}$ & 1029,43 & 1000 & 754,80 & $27 \%$ & 5,31 & 6,68 & $\mathrm{E}$ \\
\hline $\mathbf{1 5}$ & 904,20 & 800 & 822,30 & $9 \%$ & 3,85 & 6,36 & $\mathrm{~A}$ \\
\hline $\mathbf{1 6}$ & 909,59 & 800 & 764,12 & $16 \%$ & 3,90 & 6,50 & $\mathrm{~B}$ \\
\hline $\mathbf{1 7}$ & 822,22 & 800 & 716,80 & $13 \%$ & 6,38 & 6,61 & $\mathrm{~A}$ \\
\hline $\mathbf{1 8}$ & 1084,14 & 1000 & 1039,49 & $4 \%$ & 0,00 & 6,91 & $\mathrm{C}$ \\
\hline $\mathbf{1 9}$ & 805,27 & 800 & 722,65 & $10 \%$ & 5,99 & 6,98 & $\mathrm{~A}$ \\
\hline $\mathbf{2 0}$ & 797,75 & 800 & 660,67 & $17 \%$ & 4,43 & 7,09 & $\mathrm{~F}$ \\
\hline $\mathbf{2 1}$ & 801,38 & 800 & 662,13 & $17 \%$ & 4,81 & 7,20 & $\mathrm{~F}$ \\
\hline $\mathbf{F o n}$ & & & & & & \\
\hline
\end{tabular}

Fonte: As Autoras

Legenda: Peso do produto glaciado (P्PG); Peso liquido declarado ( $\left.\mathbf{P}_{\mathbf{L D}}\right)$; Peso do produto desglaciado (PPD); Percentual de glaciamento (PG).

Todas as amostras apresentaram odor caraterístico de pescado no teste de cocção e na análise sensorial não apresentaram alterações, com exceção da amostra 10, que apresentou na prova da cocção odor amoniacal e coloração não característica na avaliação sensorial, sendo possível assim correlacionar estes resultados com o da contagem microbiana, tendo em vista que esta amostra foi a que apresentou maior contagem de psicotróficos $(6,53 \log \mathrm{UFC} / \mathrm{g})$.

Quanto ao pH a legislação estabelece que deve ser no máximo de 7,00 unidades de pH (BRASIL, 2017). Logo, 14,3\% das amostras excederam este valor, como pode ser visto na Tabela 1.

O teste do gás sulfídrico também é uma das análises que contribue para verificação da qualidade do pescado, pois detecta a presença do gás sulfídrico, originado da degradação das proteínas do pescado (Brasil, 2014). Como resultado deste teste, 9,5\% das amostras apresentaram mancha mais escura enquanto que as demais apresentaram cor mais clara. 


\section{CONSIDERAÇÕES FINAIS (ou Conclusão)}

A maioria das amostras analisadas estava dentro dos limites de qualidade aceitável tanto para contagem de psicrotróficos quanto na avaliação sensorial. Entretanto, quanto ao teor de água de glaciamento e ao peso declarado ocorreram abusos nos teores encontrados indicando que os consumidores estão sendo lesados e pagando "água a preço de peixe". Estas inconsistências podem ter sido resultado de uma ação fraudulenta intencional ou de erros durante a produção, necessitando assim de uma maior supervisão durante o processamento, no controle de qualidade e na fiscalização. A inclusão da informação sobre o peso líquido drenado para peixe congelado glaciado na embalagem do produto contribuiria para um comércio mais claro e justo ao consumidor coibindo possíveis fraudes.

\section{REFERÊNCIAS}

ABREU, M. G. et al. Caracterização sensorial e análise bacteriológica do peixe-sapo (Lophius gastrophysus) refrigerado e irradiado. Ciência rural. Vol. 38, Santa Maria, 2008. p.498-503.

BRASIL. Instrução Normativa $\mathrm{n}^{\circ}$ 25, de 02 de junho de 2011. Métodos Analíticos Oficiais Físico-químicos para controle de pescados e seus derivados. Brasília, 2011. BRASIL. Ministério da Agricultura, Pecuária e Abastecimento. Laboratório Nacional Agropecuário. Laboratório de Produtos de Origem Animal. Prova de gás sulfídrico (H2S) em pescados. 2014.2 Disponível em: http://www.agricultura.gov.br/assuntos/laboratorios/legislacoes-e-metodos/arquivosmetodos-da-area-poa-iqa/met-poa-slav-21-02-prova-de-gas-sulfidrico-empescados.pdf> Acesso em 03 Ago. 2018.

BRASIL. Instrução Normativa $\mathrm{n}^{\circ} 21$, de 21 de maio de 2017. Identidade e Características de Qualidade que deve apresentar o peixe congelado. Brasília, 2017. EVANGELISTA, A. G et al. Fraudes em peixes na região central da cidade de Joinville, SC. Hig. Alimentar, v. 31, n. 274/275. 2017.

FLUGEL, G. Peixe afogado. Revista do IDEC. Ed 92, set 2005. Disponivel em: < http://www.idec.org.br/uploads/revistas_materias/pdfs/2005-09-ed92-capa-peixe.pdf> acesso em 06 ago. 2018.

FRANCO, B. G. M. B.; LANDGRAF, M. Microbiologia dos alimentos. São Paulo: Atheneu, 2008. $182 \mathrm{p}$

GONÇALVES, A. A. Estudo do processo de congelamento de camarão associado ao uso do aditivo fosfato. Tese (Doutorado em Engenharia de Produção) - Programa de Pós-Graduação em Engenharia de Produção, Universidade Federal do Rio Grande do Sul, Porto Alegre, 2005. 170 p.

NEIVA, C.R.P. et al. Glaciamento em Filé de Peixe Congelado: Revisão dos Métodos para Determinação de Peso do Produto. Bol. Inst. Pesca, São Paulo, 41(4): 899 - 906, 2015.

OETTERER, M.; SAVAY-DA-SILVA, L.K.; GALVÃO, J. A. Congelamento é o melhor método para a conservação do pescado Visão Agrícola n ${ }^{\circ} 11$ jul | dez, p. 137139, 2012.

PACHECO, et al. Análise de coliformes e bactérias mesofilicas em pescado de água doce. Hig Alimentar v.18, n.116, p. 68-72, 2004.

RIBEIRO, S. N.; MARCELLO, T. M. Avaliação da perda líquida no degelo de filés de tilápia realizada por desglaciamento. Trabalho de Conclusão de Curso (Tecnologia em Alimentos) - Universidade Tecnológica Federal do Paraná. Londrina, 2013. 38 p. 
SILVA, M. L.; MATTÉ, G. R.; MATTÉ, M. H. Aspectos sanitários da comercialização de pescado em feiras livres da cidade de São Paulo, SP/Brasil. Revista do Instituto Adolfo Lutz, São Paulo, v. 67, n. 3, p. 208-214, 2008.

SOARES, V. M. et al. Qualidade microbiológica de filés de peixe congelados distribuídos na cidade de Botucatu-SP. UNOPAR Científica. Ciências Biológicas e da Saúde. v. 13, n. 2, p. 85-88, 2011. 